\title{
The role of selected metalloproteinases and some genetic factors in the pathogenesis of abdominal aortic aneurysm
}

\author{
Stanisław Surma, Karolina Stolorz, Oskar Sierka, Aleksander L. Sieroń, Marta Lesiak \\ Department of Molecular Biology, Faculty of Medical Sciences in Katowice, Medical University of Silesia in Katowice, Poland
}

\begin{abstract}
Aortic aneurysm is defined as a pathologically dilated segment of the main artery. There are three main types of aortic aneurysms: real, pseudo and dissecting. The most common aneurysms are abdominal aortic aneurysms defined as vasodilatation equal to or above $30 \mathrm{~mm}$. Abdominal aortic aneurysm development is usually asymptomatic. Many various risk factors have been linked to AAA development. The pathophysiology of AAA is associated with inflammation, smooth muscle cells apoptosis and matrix degradation. The changes always result from imbalance between active matrix metalloproteinases (MMPS) and their inhibitors — TIMPS.

Abdominal aorta is the most common location for the aneurysm. The risk of developing AAA increases with age. It is more common in men. Its rupture is associated with a high risk of death. The pathogenesis of AAA is complex and still not fully understood. In pathophysiological processes, aortic wall degeneration and atherosclerosis dominate. The factors involved in the pathogenesis of AAA and TAA are not quite the same. Important factors involved in the formation of AAA and increasing the risk of its rupture are MMPs. Also, polymorphisms of numerous genes have been associated with the risk of developing AAA. The two groups of factors related to AAA formation and development are presented and discussed in this work.
\end{abstract}

Key words: abdominal aortic aneurysm pathogenesis; metalloproteinases; risk factors

Acta Angiol 2021; 27, I: 22-31

\section{Introduction}

Aortic aneurysm is defined as pathologically dilated segment of the main artery with loss of parallelism in its wall layers and at least $50 \%$ wider diameter of the affected artery than expected in persons of the same age and same sex [I, 2]. The correct dimensions of the aorta in adults, measured from the outer edge of the contour, are listed in Table I.

The first description of the abdominal aortic aneurysm has been provided already in the 16th century by Vesalius [3]. In the first half of the $20^{\text {th }}$ century, unsuccessful attempts were made to treat AAAs by various surgical methods. The first successful surgery of AAA with aortic reconstruction using corpse vessels was carried out by Dubost in 195I [4]. In 1965, Cooley and DeBakey introduced surgery for ascending aortic aneurysms, while in 1986 Volodos was the first who implanted a stentgraft in to the abdominal aorta $[5,6]$.

The classification of aortic aneurysms is based on different criteria. There are three main types of aortic aneurysms: real aneurysm, pseudoaneurism and dissecting aneurysm. In terms of histological structure, aortic aneurysms can be divided into two major groups baggy and fusiform. Both are true aneurysms and include all layers of the aortic wall. Fusiform aneurysms are more common. They are manifested by symmetrical widening covering the entire aortic circumference. Baggy aneurysms are less common. They are characterized by local bulge. The clinical division of aortic aneurysms is based on their location - thoracic aortic aneurysm (TAA) and abdominal aortic aneurysm (AAA). This division is important because these aneurysms are treated by 
Table I. Normal aortic dimensions in adult [2]

\begin{tabular}{|c|c|c|}
\hline Aortic segment & Diameter $(\mathbf{m m})$ & Test method \\
\hline \multirow[t]{2}{*}{ Aortic valve ring } & $W: 23 \pm 2$ & USG (transthoracic) \\
\hline & $M: 26 \pm 3$ & \\
\hline \multirow[t]{2}{*}{ Bay of Valsalva } & $W: 30 \pm 3$ & USG (transthoracic) \\
\hline & $M: 34 \pm 3$ & \\
\hline Pad of the aorta & $<37$ & USG (transthoracic) \\
\hline \multirow[t]{2}{*}{ Ascending aorta (proximal part) } & $W: 26 \pm 3$ & USG (transesophageal) \\
\hline & M: $29 \pm 3$ & \\
\hline \multirow[t]{2}{*}{ Ascending aorta } & $|4-2| / \mathrm{m}^{2}$ body surface & USG (transesophageal) \\
\hline & $25-38$ & TK \\
\hline \multirow[t]{2}{*}{ Descending aorta } & $10-16 / \mathrm{m} 2$ body surface & USG (transesophageal) \\
\hline & $17-28$ & TK \\
\hline Abdominal aorta & $|4-2|$ & USG, presentation B \\
\hline
\end{tabular}

W - woman; M - men; USG - ultrasound examination

various medical specialties [7]. The division and classification of aortic aneurysms is presented in Table 2.

The most common aneurysms are abdominal aortic aneurysms, which are defined as vasodilatation equal or above $30 \mathrm{~mm}$. Infrarenal aneurysms make up $90 \%$ of all aortic aneurysms. The incidence of AAA is gender-specific. Men are more likely to suffer from AAA. It is estimated that 3 to $9 \%$ of men over 50 years of age develop AAA, while the percentage for women over 55 years of age is I to $2 \%$. The epidemiological data indicate that the incidence of AAA increases with age. The AAA is rare in people under the age of 50 ; however, $12.5 \%$ of men and $5.2 \%$ of women aged 74 to 84 do develop AAA [8-10].

Abdominal aortic aneurysm is usually not accompanied by any specific symptoms. If any, the most common symptoms are permanent, crushing pains in the lower abdomen or lumbar region. Possible are pains that resemble spinal root pains, but the movement does not affect the intensity of the pain. AAA with a diameter above $5 \mathrm{~cm}$ may be palpated for physical examination. Often, such an aneurysm is tender, especially when it increases rapidly. However, no relationship between palpation and increased risk of AAA rupture has been associated. In auscultation, murmurs over the abdominal aorta can be heard [7]. The scant clinical manifestations of AAA result in high mortality in this disease. In addition, $78 \%$ of patients with AAA rupture die of this before reaching the hospital [I I]. Before reaching the hospital [I I]. Currently, the basic diagnostic methods for AAA detection are ultrasonography (USG) and computed tomography (CT) of the abdominal cavity.

Conservative treatment of AAA includes periodic ultrasound check-ups of the aneurysm, adequate control of blood pressure and lipid profile. The results of exper- imental studies have shown that the administration of $\beta$-blockers favorably affects the metabolism and hemodynamics of connective tissue and the durability of the aortic wall [II]. The main method of treating AAA is surgery. Every year, approximately 4.000 surgical procedures are performed in Poland for abdominal aortic aneurysm [12].

Abdominal aortic aneurysms increase their diameter at different rates. AAAs with a diameter of $40 \mathrm{~mm}$ increase their diameter by about $2.6 \mathrm{~mm} /$ year, while those with a diameter of $60 \mathrm{~mm}$ by $6.5 \mathrm{~mm} /$ year. This is related to Laplace law. The risk of AAA rupture depends on its diameter [7, 8, I3] (Table 3).

AAA rupture is associated with a high risk of death of 65 to $90 \%$ [ 14]. It accounts for approximately I I,000 deaths each year in the United States, with mortality rates from ruptured AAAs reaching up to $90 \%$ [13]. Moreover $2 \%$ of all deaths are AAA-related [10]. Smoking is a serious factor not only modulating AAA formation, but also affecting the expansion and rupture of the aneurysm. Smokers had a higher rate of annual increase in aneurysm diameter than former smokers and non-smokers. This is because the concentration of proteases, such as elastase, degrading elastin that is naturally present in the aortic wall increases [14, I5].

Numerous risk factors which can lead to AAA development have been identified. Three most important ones are age ( $>65$ years), sex (males) and cigarette smoking [16, 17]. Researches proved a positive association between development of AAA and increasing years of smoking and a negative association with smoking cessation [17]. Other risk factors include a family history of abdominal aortic aneurysm, coronary artery disease, arterial hypertension, hypercholesterolemia, peripheral artery disease (e.g., Takayasu inflammation), and previous myocardial infarction and other cardio- 
Table 2. Division and classification of aortic aneurysm

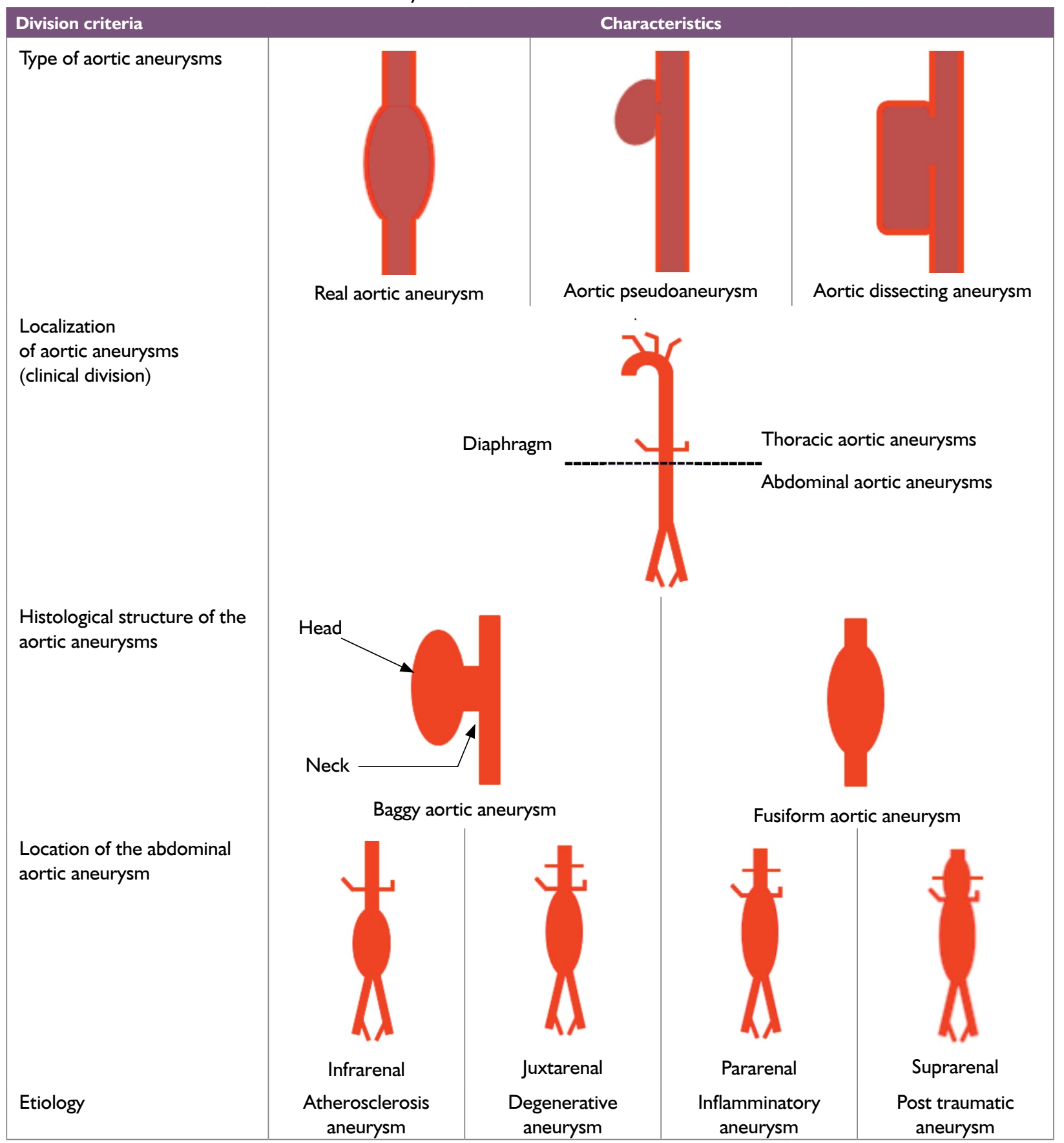

vascular diseases [18-20]. Moreover, excess weight was associated with increased risk, whereas, exercise and consumption of nuts, vegetables, and fruits were associated with reduced risk of AAA [17]. Risk factors of AAA are summarized in Figure $I$.

\section{Structure of the abdominal aorta wall}

The aorta is an elastic artery, which divides into three main parts: the ascending aorta, the arch of aorta and the descending aorta. The abdominal aorta is a part of the descending aorta, and it develops from splanchnic mesoderm [2I, 22]. It starts at the aortic hiatus of the diaphragm and ends in aortic bifurcation.

The aortic wall consists of three layers: outer adventitia, media, and inner intima (Fig. 2).

The intima has direct contact with blood. It is a single layer of endothelial cells upon loose connective tissue. It also has part called internal elastic lamina which consists of collagen and elastic fibers and a small amount of fibroblasts and smooth myocytes. The media is the widest layer; it consists of smooth muscle cells embed- 
Table 3. Relationship between the risk of rupture of the abdominal aortic aneurysm on its diameter $[7,8,13]$

\begin{tabular}{|l|c|}
\hline AAA diameter & Risk of cracking during the year (\%) \\
\hline$<4 \mathrm{~cm}$ & 0 \\
\hline $4-5 \mathrm{~cm}$ & $0.5-5$ \\
\hline $5-6 \mathrm{~cm}$ & $3-15$ \\
\hline $6-7 \mathrm{~cm}$ & $10-20$ \\
\hline $7-8 \mathrm{~cm}$ & $20-40$ \\
\hline$>8 \mathrm{~cm}$ & $30-50$ \\
\hline
\end{tabular}

An increase in AAA diameter by $5 \mathrm{~mm}$ in half a year increases the risk of rupture by 2 times

ded in a dense matrix of fibrillar structural proteins. The adventitia is made of connective tissue proper with a large number of collagen fibers, and fewer elastic fibers and smooth muscle cells. It also has ganglion cells and vasa vasorum - small blood vessels that supply the wall in nutrients. Their branches reach up to the border with tunica media $[23,24]$.

The aortic media provides viscoelasticity through concentric bands of elastin filaments with associated collagen fibers and smooth muscle cells (SMCs), which are termed lamellar units. The media of the abdominal aorta usually consists of 28 to 32 lamellar units and it is avascular - smooth muscle cells survival depends of transintimal nutrition and oxygen delivery from the plasma [25].

\section{Pathogenesis of the abdominal aortic aneurysm}

The pathophysiology of AAA is accompanied by inflammation, SMC apoptosis and matrix degradation. Once considered a consequence of advanced athero- sclerosis, evidence accumulated indicating that AAA is a focal representation of systemic cardiovascular disease [10]. Degenerative etiology dominates the pathogenesis of AAA, partly related to the atherosclerotic process [26]. In both AAA and TAA, the amount of elastin, collagen and glycosaminoglycans are reduced compared to normal aortas. Imbalance between the amount of active MMPs and their inhibitors - TIMPs - are responsible for the majority of the above listed pathological changes $[27,28]$. MMPs are members of the metzincin group of proteases, which are named due to the zinc ion and the conserved Met residue at the active site [29]. The main inhibitor of MMPs is glycoprotein - TIMP-I. The second TIMP is non-glycosylated protein, produced by fibroblasts and endothelial cells and called TIMP-2. TIMP-I expression is regulated by interleukin I (IL-I) and tumor necrosis factor alpha (TNF- $\alpha$ ). No effect of cytokines on TIMP-2 has been demonstrated [30]. Metalloproteinases in a healthy aorta are produced by endothelial cells, SMCs and fibroblasts. Additional sources of these enzymes were observed in AAA, which led to an imbalance in ratio of MMP to TIMP [3 I]. Different MMPs play a major role in the pathogenesis of TAA and AAA (Fig. 3).

In addition to the MMP/TIMP system, immune cells, the renin-angiotensin-aldosterone system, the inflammatory process and oxygen free radicals play an important role in the pathogenesis of AAA [3I].

\section{The role of MMP-I in the pathogenesis of AAA}

Metalloproteinase I (collagenase I; MMP-I) is an enzyme involved in the digestion of collagen fibers. Increased MMP-I gene expression was found in patients with AAA while the level of its inhibitors was reduced [32]. Inflammatory cells are a small source of MMP-I [33].

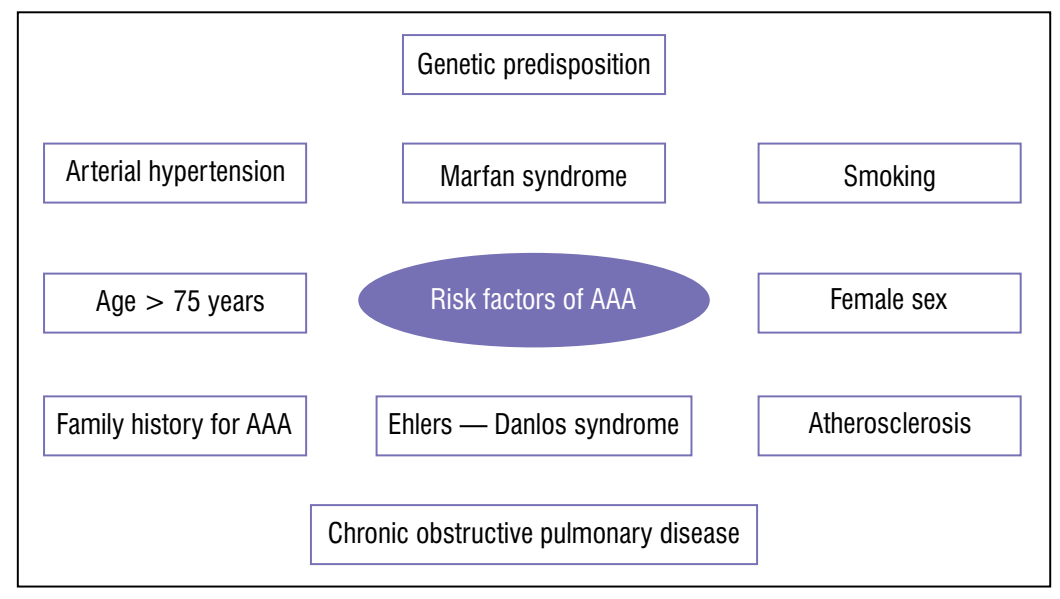

Figure I. Risk factors for abdominal aortic aneurysm (AAA) [I3, 2I] 


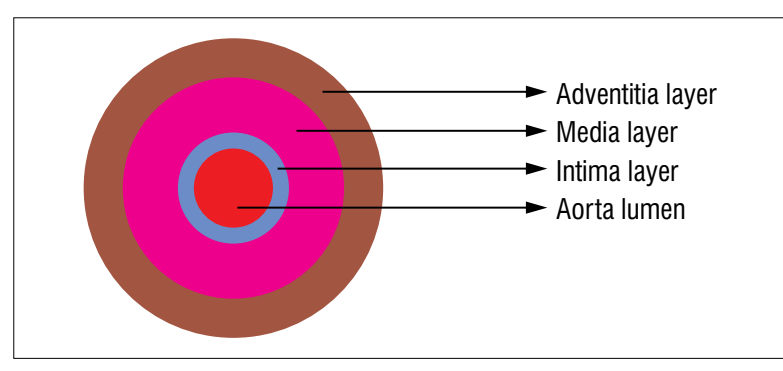

Figure 2. Schematic structure of the abdominal aorta wall

It has been shown that the presence of elevated MMPI concentration in the aortic wall is associated with elevated risk of rupture [34].

\section{The role of MMP-2 in the pathogenesis of AAA}

The main role of MMP-2 in human tissue is degradation of both type IV collagen, which is an important component of basal membranes, and denatured collagen [35]. MMP-2's role in abdominal aorta aneurysm relies on degradation of the intercellular substance of the aortic wall, which can lead to its rupture. Under normal conditions, the process of changes in vascular tissue is controlled by the balance between the action of MMP and their inhibition, which involves TIMPs.

Increased expression of MMP-2 has been observed not only in the blood of patients suffering from AAA but also in the AAA tissue [16], which further increased the likelihood of AAA wall rapture.

\section{The role of MMP-3 in the pathogenesis of AAA}

MMP-3 (stromelysin I) is responsible for digesting collagen and several other extracellular matrix proteins, which are important in maintaining the structural integrity of the aortic wall and pericellular activation of proMMPs. For example it is necessary for transformation of the proMPP-I zymogen into fully active MMP-I. Immunohistochemical studies have previously revealed the expression of stromelysin- I in abdominal aortic aneurysm in relation to macrophages present within the aortic wall. Thus, this additionally supported the idea that aneurysm expansion is due to a chronic inflammatory process [36].

Upregulation of stromelysin-I and TIMP-3 expression may play a significant role in the expansion of an atherosclerotic aorta to form an aneurysm. It seems plausible that excessive production of stromelysin- I in an atherosclerotic aorta weakens the aortic wall and causes additional prote- olysis by activating other latent, constitutively expressed metalloproteinases [37]. MMP-3 contributes to plaque destabilization and promotes TAA formation by degrading the elastic lamina, and therefore plays an important role in aneurysm formation. MMP-3 was shown to degrade type IV collagen, fibronectin, laminin, proteoglycan core protein, and type IX collagen [38].

Results of genetic study revealed that the $5 \mathrm{~A}$ allele in the promoter region of the MMP-3 gene occurs more frequently in AAA patients. This study also showed a link between the $5 \mathrm{~A} / 5 \mathrm{~A}$ genotype and intensity of MMP-3 gene expression. The aortic aneurysmal wall of patients, who were homozygous for the 5A-allele, contained larger quantities ( $>45 \%$ ) of MMP-3 protein than the wall from $5 \mathrm{~A} / 6 \mathrm{~A}$ heterozygotes; suggesting that the $5 \mathrm{~A}$-allele causes increase in MMP-3 production in these patients [39]. Meta-analysis of genes or putative AAA-related genes showed their positive correlation between MMP-3 rs3025058 polymorphism and a higher risk of AAA development [40].

\section{The role of MMP-9 in the pathogenesis of AAA}

MMP-9, also, called gelatinase B or type IV collagenase, is the metalloproteinase, which has three repeats of a type II fibronectin domain inserted in the catalytic domain through which the proteinase interacts with gelatin, collagens, and laminins [36]. Numerous cytokines are able to regulate MMP-9 expression, but the major role in it has TNF- $\alpha$. At the transcriptional level an important positive regulator is nuclear factor- $\kappa \mathrm{B}(\mathrm{NF}-\kappa \mathrm{B})$ [40]. ECM proteins which are proteolytically processed by MMP-9 include collagen, elastin, fibronectin, and laminin [4I].

MMP-9 is responsible for degradation of ECM proteins at the aortic wall. In the pathogenesis of AAA, a major role has inflammatory response in the endothelial, medial, and adventitial layers. Besides monocytes, other cells secreting MMP-9, such as macrophages and neutrophils, participate in this process. The activity of monocytes is modulated by proinflammatory cytokines, for example TNF- $\alpha$, which can promote the secretion of MMPs via MAPK pathway [4I]. Increased angiogenesis was also detected in the aneurysm wall [42] as a result of MMP-9-stimulated release of VEGF [43], the factor which stimulates angiogenesis.

Activation of TGF- $\beta$ may be one of the ways in which MMP-2 and MMP-9 work together. Although it is generally believed that the activation of the TGF$\beta$ signaling pathway offers protection against AAA development, it also has important roles in enhancing Type I and III collagen production, and increasing expression of protease inhibitors, plasminogen activator inhibitor-I (PAI-I) and TIMP-I [44]. 


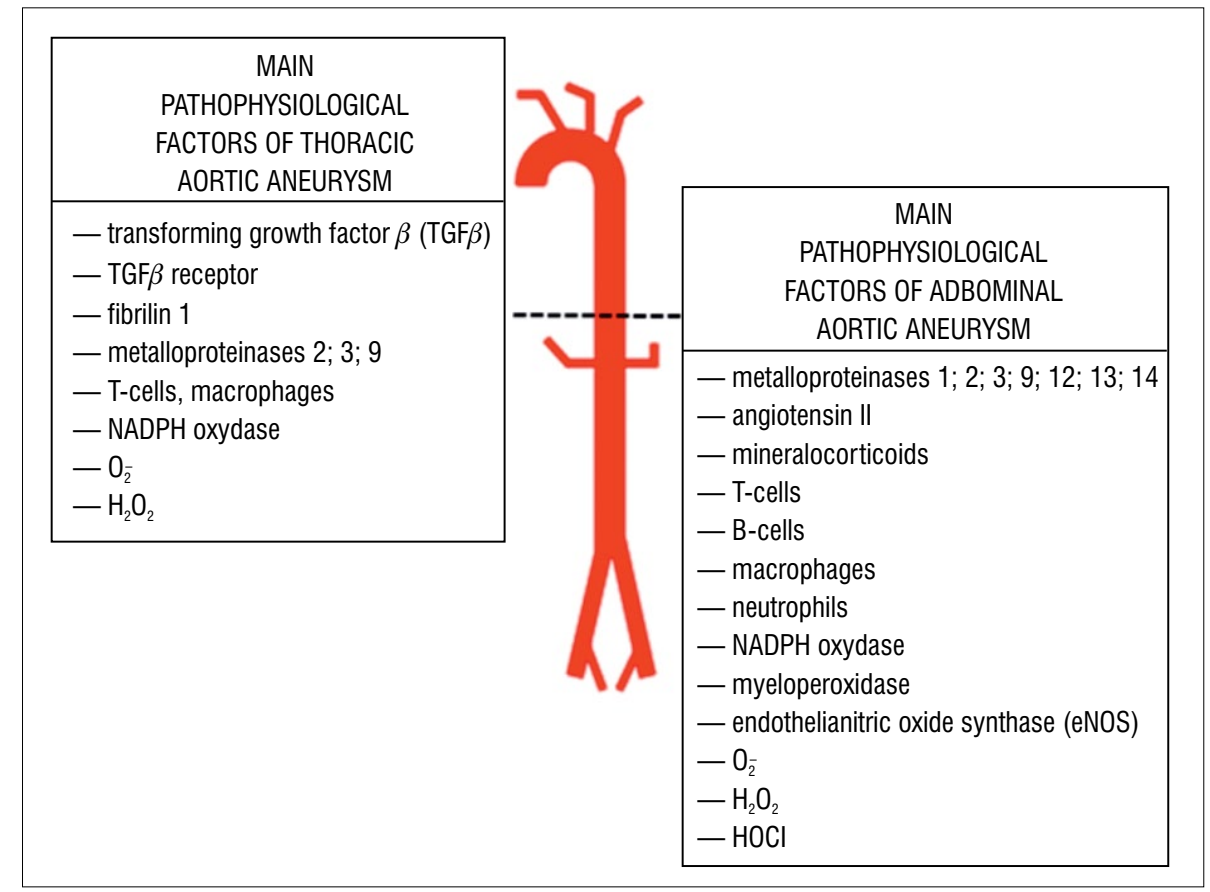

Figure 3. Factors affecting the pathophysiology of thoracic aortic aneurysm (TAA) and abdominal aortic aneurysm (AAA). Based on $[31]$

Correlation of MMP-9 concentration with maximum aortic diameter was considered a clinical marker of AAA growth. MMP-9 activity varies depending on the diameter of the aorta. Its expression is increased in aneurysms with a diameter of 5 to 6 or even $9 \mathrm{~cm}[45,46]$.

\section{The role of MMP-I 2 in the pathogenesis of AAA}

The main source of MMP- 12 (metalloelastase) in the aortic wall are macrophages [47]. However, the role of this metalloproteinase in the pathogenesis of AAA is not completely understood. Results of experimental studies have shown that MMP-I 2 knockout (KO) mice have developed AAA. Interestingly, mice with $\mathrm{KO}$ of MMP- 12 and MMP-9 and KO of MMP-9 alone did not develop AAA [48]. It is currently indicated that MMPI 2 cannot be directly involved in the pathogenesis of AAA but apparently helps other MMPs in extracellular matrix degradation [3I].

\section{The role of MMP-I 3 in the pathogenesis of AAA}

The main source of MMP-I 3 (collagenase 3) are SMCs in the aortic wall. MMP- 13 expression is increased in AAA people, especially in symptomatic AAA and in AAA with a high risk of rupture $[49,50]$ In genetic stud- ies it has been shown that polymorphism $(-77 \mathrm{~A} / \mathrm{G})$ is a significant independent risk factor for AAA formation. These results indicated that MMP-I 3 plays an important role in the pathogenesis of AAA [31,32].

\section{The role of MMP-I4 in the pathogenesis of AAA}

MMP-I4 (membrane type I MMP) is produced by macrophages and SMCs in the aortic wall. Clinical studies have shown that patients with AAA showed elevated MMP- I 4 gene expression [ $5 \mathrm{I}$ ]. Experimental studies have also shown that in mice with $\mathrm{CaCl}_{2}$-induced AAAMMP- 14 derived from macrophages played a key role in direct degradation of the extracellular matrix, which led to the development of AAA. It was found that MMP- 14 directly regulated the elastolytic activity of macrophages [52].

\section{Selected genetic-related factors associated with AAA}

First reports on possible genetic background of AAA were published in 1977 when the article about three brothers, surgically treated for ruptured, previously symptomless AAA, was published [53].

In 2016 Bradley and colleagues performed a meta-analysis and systematic review of the available literature to show which factors are genuine and which may 
be caused by type I errors, biases, and differences in study design [54]. The most important genetic variants are described briefly as follow:

I. 9p2 I rs I 0757278 - one of several polymorphism clustered together in a region of chromosome 9 that has been linked to increased risk of heart disease, abdominal obesity, dyslipidemia, hypertension and, potentially, diabetes. The overall estimate of heart disease cases that may involve this SNV (or related ones nearby) is said to be $20-30 \%$ [55]. Genome-wide association studies (GWAS) have identified a 9p2 I as a major risk locus for coronary artery disease and myocardial infarction. All of the listed factors can lead to development of AAA [56]. 2. SORTI rs599839 — SORTI gene on chromosome I, carries information about protein called sortilin. Sortilin is a transmembrane protein primarily found in brain tissue. It is recognized as a major player in different processes of atherogenesis. Research results suggest that sortilin has a significant role in the pathogenesis of vascular and metabolic disorders through contributions to inflammation and calcification of arterial wall. Moreover, sortilin might play role in dysregulation of lipoprotein metabolism and type II diabetes mellitus [57]. 3. LRPI rs|466535 - association between the rs I466535 SNV in the gene of low density lipoprotein receptor-related protein I (LRPI) and abdominal aortic aneurysm was showed by GWAS conducted by Bown et al. [58]. Later this association was also confirmed by a group of Italian scientists led by Silvia Galora and Claudia Saracini [59]. Despite the evidence provided by the two reports, it is not certain if the association is specific for aneurysmal disease or the atherosclerotic process [60]. 4. MMP3 rs3025058 - SNV rs3025058 was first described in 1995 as a variant located upstream of MMP3 and influencing the regulation of this gene expression. The role of MMP3 proteinase was presented in previous sections of this review.

5. AGTRI rs5I86 - rs5I86, a SNV, also, known as $+1166 \mathrm{~A} / \mathrm{C}$ or Al I66C is located in the 3 ' untranslated region of $A G T R I$ mRNA. It is among the most studied of over 50 SNVs in AGTRI [6I]. AGTRI is a part of the renin-angiotensin system. Its physiological role is regulation of blood pressure and the balance of fluids and salts in the body. Angiotensin II (created in renin-angiotensin cascade) binds to the ATI receptor in the blood vessels and stimulates them to constrict what results in increased blood pressure. Binding of angiotensin II to the ATI receptor also stimulates production of aldosterone, a hormone that triggers the absorption of water and salt in the kidneys. The increased amount of fluid in the body also increases blood pressure [62]. As listed previously, elevated blood pressure is a risk factor of AAA development.
6. ACE rs4646994 - rs4646994 is one of four SNVs representing perhaps the best studied ACE SNV. It is actually not a single nucleotide variant at all; instead, it is an insertion/deletion of an Alu repetitive element in an intron of the ACE gene. Alleles containing the insertion are called "I" alleles, and "D" alleles lack the repetitive element [63]. Function of angiotensin-converting enzyme (ACE) is catalysis of the cleavage of the angiotensin I into the active octamer the angiotensin II, which contributes to hypertension by inducing smooth muscle in the vessels to constriction and renal tubule sodium reabsorption [64].

7. APOAI rs964I84 - The rs964I84 (G;G) genotype is associated with hypertriglyceridemia [65]. The APOAI encodes a protein called apolipoprotein A-I (apoA-I). It is a component of high-density lipoprotein (HDL). HDL is a molecule that transports cholesterol and phospholipids through the bloodstream from the body's tissues to the liver. Once in the liver, cholesterol and phospholipids are redistributed to other tissues or removed from the body. ApoA-I attaches to cell membranes and promotes the movement of cholesterol and phospholipids from inside the cell to the outer surface. Once outside the cell, these substances combine with ApoA-I to form HDL. ApoA-I also triggers a reaction called cholesterol esterification that converts cholesterol to a form that can be fully integrated into HDL and transported through the bloodstream. Hypertriglyceridemia, which can develop easier in a group of patients with this gene variant, is a one of many causes of atherosclerosis [65].

\section{Summary and conclusions}

I. The abdominal aortic aneurysm is the most common location for this condition.

A) The risk of developing AAA increases with age.

B) It is more common in men. AAA rupture is associated with a high risk of death.

2. Abdominal aortic aneurysm most often is asymptomatic, which hinders its early detection and treatment.

3. The pathogenesis of AAA is complex and still not fully understood. The most important processes in the pathophysiology of AAA are degeneration and atherosclerosis of the arterial wall.

4. The factors involved in the pathogenesis of AAA and TAA are not quite the same.

5. Important compounds involved in the formation of AAA and increasing the risk of its rupture are some of the extracellular matrix metalloproteinases.

6. Genetic variants of numerous genes are associated with the risk of developing AAA. 
7. More research is needed into the pathogenesis of AAA and identification of biomarkers that would enable early detection of this disease.

\section{Conflict of interest:}

None.

\section{References:}

I. Davis FM, Rateri DL, Daugherty A. Abdominal aortic aneurysm: novel mechanisms and therapies. Curr Opin Cardiol. 2015; 30(6): 566-573, doi: 10.1097/HCO.0000000000000216, indexed in Pubmed: 26352243.

2. Mao SS, Ahmadi N, Shah B, et al. Normal thoracic aorta diameter on cardiac computed tomography in healthy asymptomatic adults: impact of age and gender. Acad Radiol. 2008; 15(7): 827-834, doi: 10.1016/j.acra.2008.02.00I, indexed in Pubmed: 18572।I7.

3. Noszczyk W. Rys historyczny leczenia chorób naczyń. In: Noszczyk W. ed. Chirurgia tętnic i żył obwodowych. PZWL, Warszawa 2007: 3-19.

4. Dubost C. The first successful resection of an aneurysm of the abdominal aorta followed by re-establishment of continuity using a preserved human arterial graft. Ann Vasc Surg. 1986; I(I): 147-149, doi: 10.1016/50890-5096(06)607/8-8, indexed in Pubmed: 3333006.

5. Debakey ME, henly WS, cooley DA, et al. Surgical management of dissecting aneurysms of the aorta. J Thorac Cardiovasc Surg. 1965; 49: 130-149, indexed in Pubmed: |4261867.

6. Volodos' NL, Shekhanin VE, Karpovich IP, et al. [A self-fixing synthetic blood vessel endoprosthesis]. Vestn Khir Im I I Grek. 1986; 137(11): 123-125, indexed in Pubmed: 3824776.

7. Sakalihasan N, Michel JB, Katsargyris A, et al. MR imaging of iron phagocytosis in intraluminal thrombi of abdominal aortic aneurysms in humans. Radiology. 2010; 254(3): 973-981, doi: 10.1 148/radiol.09090657, indexed in Pubmed: 20177108.

8. Hirsch A, Haskal Z, Hertzer N, et al. ACC/AHA 2005 Practice Guidelines for the Management of Patients With Peripheral Arterial Disease (Lower Extremity, Renal, Mesenteric, and Abdominal Aortic). Circulation. 2006; I I3(1 I): 463-1654, doi: 10.1 I6I/ circulationaha. 106.174526.

9. Jamrozik K, Norman PE, Spencer CA, et al. Screening for abdominal aortic aneurysm: lessons from a population-based study. Med J Aust. 2000; 173(7): 345-350, doi: 10.5694/j. I3265377.2000.tb |25684.x, indexed in Pubmed: I 1062788.

10. Nordon IM, Hinchliffe RJ, Malkawi AH, et al. Modern treatment of juxtarenal abdominal aortic aneurysms with fenestrated endografting and open repair--a systematic review. Eur J Vasc Endovasc Surg. 2009; 38(I): 35-4I, doi: 10.1016/j.ejvs.2009.02.012, indexed in Pubmed: 19346। 40.

II. Fillinger M. Abdominal Aortic Aneurysms. Rutherford's Vascular Surgery. 2010: 1928-1948, doi: 10.1016/b978-1-4160-52234.00127-x.

12. Studzińska D, Rudel B, Lewandowski K, et al. The prevalence of renal vascular and anatomical anomalies in patients with abdominal aortic aneurysm. Chir Pol. 2018; 20: 31-34.

13. Correction. Circulation. 2012; 125(8), doi: 10.1 16I/cir.0b0I3e31824da922.

14. Khan S, Verma V, Verma S, et al. Assessing the potential risk of rupture of abdominal aortic aneurysms. Clin Radiol. 2015; 70(I):
II-20, doi: 10.1016/j.crad.2014.09.016, indexed in Pubmed: 25544065.

15. Ruptured Abdominal Aortic Aneurysm. Definitions. 2020, doi: 10.32388/heusqi.

16. Keisler B, Carter C. Abdominal aortic aneurysm. Am Fam Physician. 20I5; 9 I (8): 538-543, indexed in Pubmed: 2588486I.

17. Kent KC, Zwolak RM, Egorova NN, et al. Analysis of risk factors for abdominal aortic aneurysm in a cohort of more than 3 million individuals. J Vasc Surg. 2010; 52(3): 539-548, doi: 10.1016/j. jvs.2010.05.090, indexed in Pubmed: 20630687.

18. Altobelli E, Rapacchietta L, Profeta VF, et al. Risk Factors for Abdominal Aortic Aneurysm in Population-Based Studies: A Systematic Review and Meta-Analysis. Int J Environ Res Public Health. 2018; I5(I2), doi: 10.3390/ijerph I5 I22805, indexed in Pubmed: 30544688.

19. Stackelberg O, Wolk A, Eliasson K, et al. Lifestyle and Risk of Screening-Detected Abdominal Aortic Aneurysm in Men. J Am Heart Assoc. 2017; 6(5), doi: 10.1161/JAHA.116.004725, indexed in Pubmed: 28490522.

20. Blanchard JF, Armenian HK, Friesen PP. Risk factors for abdominal aortic aneurysm: results of a case-control study. Am J Epidemiol. 2000; 15I(6): 575-583, doi: 10.1093/oxfordjournals. aje.a010245, indexed in Pubmed: 10733039.

21. Cornuz J, Sidoti Pinto C, Tevaearai H, et al. Risk factors for asymptomatic abdominal aortic aneurysm: systematic review and meta-analysis of population-based screening studies. Eur J Public Health. 2004; 14(4): 343-349, doi: 10.1093/eurpub/14.4.343, indexed in Pubmed: I5542867.

22. Tromp G, Kuivaniemi H, Hinterseher I, et al. Novel genetic mechanisms for aortic aneurysms. Curr Atheroscler Rep. 2010; 12(4): 259-266, doi: 10.1007/s | |883-010-01 II-x, indexed in Pubmed: 20446064.

23. Ruddy JM, Jones JA, Spinale FG, et al. Regional heterogeneity within the aorta: relevance to aneurysm disease. J Thorac Cardiovasc Surg. 2008; 136(5): I|23-I|30, doi: 10.1016/j. jtcvs.2008.06.027, indexed in Pubmed: |9026791.

24. Sawicki W, Malejczyk J. Histologia. PZWL, Warszawa 2012: 326-327.

25. Wolinsky H. Comparison of medial growth of human thoracic and abdominal aortas. Circ Res. 1970; 27(4): 531-538, doi: 10.1 161/01.res.27.4.531, indexed in Pubmed: 5507030.

26. Wytyczne ESC. dotyczące rozpoznawania i leczenia chorób aorty w 2014 roku. Kardiol Pol. 20 I4; 72: I I69-1252.

27. Fanjul-Fernández M, Folgueras AR, Cabrera S, et al. Matrix metalloproteinases: evolution, gene regulation and functional analysis in mouse models. Biochim Biophys Acta. 2010; 1803(I): 3-19, doi: 10.1016/j.bbamcr.2009.07.004, indexed in Pubmed: 19631700.

28. Kadoglou NP, Liapis CD. Matrix metalloproteinases: contribution to pathogenesis, diagnosis, surveillance and treatment of abdominal aortic aneurysms. Curr Med Res Opin. 2004; 20(4): 419-432, doi: 10.1185/030079904/25003143, indexed in Pubmed: 15119978.

29. Page-McCaw A, Ewald AJ, Werb Z. Matrix metalloproteinases and the regulation of tissue remodelling. Nat Rev Mol Cell Biol. 2007; 8(3): 22I-233, doi: 10.1038/nrm2125, indexed in Pubmed: 17318226 .

30. Arpino V, Brock M, Gill SE. The role of TIMPs in regulation of extracellular matrix proteolysis. Matrix Biol. 2015; 44-46: 247-254, doi: 10.1016/j.matbio.2015.03.005, indexed in Pubmed: 25805621 . 
31. Quintana RA, Taylor WR. Cellular Mechanisms of Aortic Aneurysm Formation. Circ Res. 2019; 124(4): 607-618, doi: 10.1161/ CIRCRESAHA. I I8.313187, indexed in Pubmed: 30763207.

32. Saracini C, Bolli P, Sticchi E, et al. Polymorphisms of genes involved in extracellular matrix remodeling and abdominal aortic aneurysm. J Vasc Surg. 20 12; 55(I): I7I-179.e2, doi: 10.1016/j. jvs.201 I.07.05I, indexed in Pubmed: 22094II 7.

33. Newman KM, Jean-Claude J, Li H, et al. Cellular localization of matrix metalloproteinases in the abdominal aortic aneurysm wall. J Vasc Surg. 1994; 20(5): 814-820, doi: 10.1016/s074I52।4(94)70169-5, indexed in Pubmed: 7526009.

34. Courtois A, Nusgens BV, Hustinx R, et al. I8F-FDG uptake assessed by PET/CT in abdominal aortic aneurysms is associated with cellular and molecular alterations prefacing wall deterioration and rupture. J Nucl Med. 2013; 54(10): 1740-1747, doi: 10.2967/jnumed. I I 2. I I5873, indexed in Pubmed: 24009278.

35. Morgunova E, Tuuttila A, Bergmann U, et al. Structure of human pro-matrix metalloproteinase-2: activation mechanism revealed. Science. 1999; 284(5420): 1667-1670, doi: 10.1 126/ science.284.5420.1667, indexed in Pubmed: 10356396.

36. Visse R, Nagase H. Matrix metalloproteinases and tissue inhibitors of metalloproteinases: structure, function, and biochemistry. Circ Res. 2003; 92(8): 827-839, doi: 10.1161/01. RES.0000070 I | 2.807| I.3D, indexed in Pubmed: | $2730 \mid 28$.

37. Carrell TWG, Burnand KG, Wells GMA, et al. Stromelysin-I (matrix metalloproteinase-3) and tissue inhibitor of metalloproteinase- 3 are overexpressed in the wall of abdominal aortic aneurysms. Circulation. 2002; 105(4): 477-482, doi: 10.1161/ hc0402.102621, indexed in Pubmed: I 1815431.

38. Theruvath TP, Jones JA, Ikonomidis JS. Matrix metalloproteinases and descending aortic aneurysms: parity, disparity, and switch. J Card Surg. 2012; 27(I): 81-90, doi: 10.1 III/j.15408191.2011.01315.x, indexed in Pubmed: 21958052.

39. Deguara J, Burnand KG, Berg J, et al. An increased frequency of the $5 \mathrm{~A}$ allele in the promoter region of the MMP3 gene is associated with abdominal aortic aneurysms. Hum Mol Genet. 2007; 16(24): 3002-3007, doi: 10.1093/hmg/ddm258, indexed in Pubmed: 17875574.

40. Morris DR, Biros E, Cronin O, et al. The association of genetic variants of matrix metalloproteinases with abdominal aortic aneurysm: a systematic review and meta-analysis. Heart. 2014; 100(4): 295-302, doi: 10.1 |36/heartjnl-2013-304/29, indexed in Pubmed: 23813847.

41. Ramella M, Boccafoschi F, Bellofatto K, et al. Endothelial MMP-9 drives the inflammatory response in abdominal aortic aneurysm (AAA). Am J Transl Res. 2017; 9(12): 5485-5495, indexed in Pubmed: 293। 2500 .

42. Kunecki M, Danilewicz M, Nawrocka-Kunecka A. Usefulness of serum VEGF concentration measurement to estimate aortic aneurysm risk of rupture. Acta Angiol. 2006; 12: 7-15.

43. Bergers G, Brekken R, McMahon G, et al. Matrix metalloproteinase-9 triggers the angiogenic switch during carcinogenesis. Nat Cell Biol. 2000; 2(10): 737-744, doi: 10.1038/35036374, indexed in Pubmed: I 1025665.

44. Aortic Aneurysm and Aortic Dissection. 2020, doi: 10.5772/ intechopen.78173.

45. Fic P, Zakrocka I, Kurzepa J, et al. [Matrix metalloproteinases and atherosclerosis]. Postepy Hig Med Dosw (Online). 201 I; 65: 16-27, doi: 10.5604/I7322693.93 I536, indexed in Pubmed: 2135799 I.
46. Trojanek BJ. Rola metaloproteinaz macierzy zewnątrzkomórkowej i tkankowych inhibitorów metaloproteinaz w nadciśnieniu tętniczym. Patogeneza nadciśnienia a problem otyłości. Post Bioch. 2015; 61: 356-58.

47. Johnson JL. Metalloproteinases in atherosclerosis. Eur J Pharmacol. 2017; 816: 93-106, doi: 10.1016/j.ejphar.2017.09.007, indexed in Pubmed: 28893577.

48. Pyo R, Lee JK, Shipley JM, et al. Targeted gene disruption of matrix metalloproteinase-9 (gelatinase B) suppresses development of experimental abdominal aortic aneurysms. J Clin Invest. 2000; I05(II): 164I-1649, doi: 10.1 I72/JCl8931, indexed in Pubmed: 10841523.

49. Mao D, Lee JK, VanVickle SJ, et al. Expression of collagenase-3 (MMP-13) in human abdominal aortic aneurysms and vascular smooth muscle cells in culture. Biochem Biophys Res Commun. 1999; 26I(3): 904-910, doi: 10.1006/bbrc.1999.1142, indexed in Pubmed: 10441523.

50. Tromp G, Gatalica Z, Skunca M, et al. Elevated expression of matrix metalloproteinase- 13 in abdominal aortic aneurysms. Ann Vasc Surg. 2004; 18(4): 414-420, doi: 10.1007/s 100 I6-0040050-5, indexed in Pubmed: 15156361 .

5I. Nollendorfs A, Greiner TC, Nagase H, et al. The expression and localization of membrane type-I matrix metalloproteinase in human abdominal aortic aneurysms. J Vasc Surg. 200I; 34(2): 316-322, doi: 10.1067/mva.2001.115962, indexed in Pubmed: II496285.

52. Xiong W, Knispel R, MacTaggart J, et al. Membrane-type I matrix metalloproteinase regulates macrophage-dependent elastolytic activity and aneurysm formation in vivo. J Biol Chem. 2009; 284(3): 1765-177|, doi: 10.1074/jbc.M806239200, indexed in Pubmed: 19010778.

53. Clifton MA. Familial abdominal aortic aneurysms. Br J Surg. 1977; 64(II): 765-766, doi: 10.1002/bjs.180064/102, indexed in Pubmed: 588966.

54. Bradley DT, Badger SA, McFarland M, et al. Abdominal Aortic Aneurysm Genetic Associations: Mostly False? A Systematic Review and Meta-analysis. Eur J Vasc Endovasc Surg. 2016; 51 (1): 64-75, doi: 10.1016/j.ejvs.2015.09.006, indexed in Pubmed: 26460285

55. https://www.snpedia.com/index.php/Rs 10757278 (I.12.2019).

56. Bayoglu B, Cakmak HA, Yuksel H, et al. Chromosome 9p2I rs 10757278 polymorphism is associated with the risk of metabolic syndrome. Mol Cell Biochem. 2013; 379(I-2): 77-85, doi: 10.1007/s | I010-013-1629-3, indexed in Pubmed: 23535969.

57. Goettsch C, Kjolby M, Aikawa E. Sortilin and Its Multiple Roles in Cardiovascular and Metabolic Diseases. Arterioscler Thromb Vasc Biol. 2018; 38(I): 19-25, doi: 10.1161/ATVBAHA. 1 1 7.310292, indexed in Pubmed: 29191923.

58. Bown MJ, Jones GT, Harrison SC, et al. CARDloGRAM Consortium, Global BPgen Consortium, DIAGRAM Consortium, VRCNZ Consortium. Abdominal aortic aneurysm is associated with a variant in low-density lipoprotein receptor-related protein I. Am J Hum Genet. 201 I; 89(5): 619-627, doi: 10.1016/j. ajhg.20II.10.002, indexed in Pubmed: 22055160.

59. Galora S, Saracini C, Pratesi G, et al. Association of rs 1466535 LRPI but not rs3019885 SLC30A8 and rs6674I7I TDRDI0 gene polymorphisms with abdominal aortic aneurysm in Italian patients. J Vasc Surg. 2015; 6I(3): 787-792, doi: 10.1016/j. jvs.2013. 10.090, indexed in Pubmed: 24423473. 
60. Giusti B, Galora S, Saracini C, et al. Role of rs $\mid 466535$ low density lipoprotein receptor-related protein I (LRPI) gene polymorphism in carotid artery disease. Atherosclerosis. 2014; 237(I): 135-137, doi: 10.1016/j.atherosclerosis.2014.08.049, indexed in Pubmed: 2523822।.

61. https://www.snpedia.com/index.php/Rs5186 (1.12.2019).

62. https://ghr.nlm.nih.gov/gene/AGTRI (I.12.2019).
63. https://www.snpedia.com/index.php/Rs4646994 (I.12.2019).

64. Crackower MA, Sarao R, Oudit GY, et al. Angiotensin-converting enzyme 2 is an essential regulator of heart function. Nature. 2002; 4I7(6891): 822-828, doi: 10.1038/nature00786, indexed in Pubmed: 12075344.

65. https://www.snpedia.com/index.php/Rs964I84 (I.12.2019). 